\title{
RESEARCH
}

\section{Using Social Cognitive Theory to Explain the Intention of Final-year Pharmacy Students to Undertake a Higher Degree in Pharmacy Practice Research}

\author{
Stephen R. Carter, PhD, Rebekah J. Moles, PhD, Ines Krass, PhD, Vicki S. Kritikos, PhD \\ University of Sydney, Sydney, New South Wales, Australia \\ Submitted May 4, 2015; accepted September 11, 2015; published August 25, 2016.
}

Objective. To develop and test a conceptual model that hypothesized student intention to undertake a higher degree in pharmacy practice research (PPR) would be increased by self-efficacy, outcome expectancy, and the social influence of faculty members.

Methods. Cross-sectional surveys were completed by 387 final-year pharmacy undergraduates enrolled in 2012 and 2013. Structural equation modeling was used to explore relationships between variables and intention.

Results. Fit indices were good. The model explained 55\% of the variation in intention. As hypothesized, faculty social influence increased self-efficacy and indirectly increased outcome expectancy and intention.

Conclusion. To increase pharmacy students' orientation towards a career in PPR, faculty members could use their social influence by highlighting PPR in their teaching.

Keywords: Students, pharmacy, practice research, self-confidence, social norms, psychosocial

\section{INTRODUCTION}

Ever since Hepler and Strand's seminal work advocating for the provision of pharmaceutical care, ${ }^{1}$ nontraditional services in pharmacy practice have increased throughout the world. This expansion of the of pharmacist's role has been accompanied by increasing inclusion of social and administrative pharmacy content embedded in pharmacy curriculum. ${ }^{2}$ Along with the need for students to learn social and administrative pharmacy content is the need for them to develop research skills in preparation for emerging roles and those in clinical pharmacy. ${ }^{3}$

Training in pharmacy practice research (PPR) is an accepted component of professional pharmacy degrees in Australia and New Zealand, ${ }^{4}$ the United States, ${ }^{5}$ the United Kingdom, ${ }^{6}$ and Canada. ${ }^{7}$ Further, the Australian Pharmacy Council stipulates that each college or school of pharmacy must actively promote and support research and scholarship. ${ }^{4}$ Commentary from the United States further supports the need for the inclusion of research skills training in professional (doctoral) pharmacy programs. ${ }^{8}$ There may be a high level of diversity in the breadth and depth of PPR skills training offered by professional degree programs. Whether students are exposed to sufficient training for

Corresponding Author: Stephen R. Carter, Room 509

Building A15 University of Sydney, Sydney, New South Wales, Australia Telephone: +61 29251 5278. E-mail: stephen. carter@sydney.edu.au
PPR is questioned in the United States ${ }^{9}$ and Arabicspeaking countries. ${ }^{10}$ While further research is needed to determine the effectiveness of PPR training (in terms of academic outcomes), this paper deals with students' subjective experiences of PPR and their career goals.

Research and innovation are drivers for change and moulded the evidenced-based practice paradigm. Without practice research, the profession would stagnate and patients might not experience the potential benefits of expanded pharmacy services and standards of care. Research is needed to understand how best to design, implement, and evaluate outcomes of expanded services. Furthermore, as the profession expands and pharmacists pursue the opportunity to practice at an advanced level, research skills will become increasingly pertinent. ${ }^{11}$ In Australia, a new framework for the recognition of advanced practice has been developed, which states that advanced pharmacy practitioners will need to demonstrate research skill competencies. ${ }^{12}$ While it specifically assumes, for example, that all pharmacists need to be able to interpret research findings and integrate them into their practice, ${ }^{4}$ advanced pharmacy practitioners, akin to the medical model, will be required to actively participate in PPR. ${ }^{12}$ Advanced practitioners may be expected to, for example, conduct prescribing practice audits, implement the results of trial data into local practice procedures, and develop evidence-based 


\section{American Journal of Pharmaceutical Education 2016; 80 (6) Article 95.}

treatment guidelines, protocols, or standards of practice at a local or national level. ${ }^{13}$

The number of Australian pharmacists working in roles that include a large component of research is probably not high. Health Workforce Australia (HWA), a statutory authority charged with building a sustainable health workforce, reported that, in 2012-2013, less than 3\% of registered pharmacists were employed in academia or research. ${ }^{14}$ The report also suggested, however, that the recent increase in supply of pharmacists should be seen as "an opportunity to further pursue changing models of care and work settings, and opportunities for expanded scope of practice for pharmacists." 14 As opportunities for PPR expand, there will be a need for more pharmacy practice researchers.

In Australia, there is some discussion as to whether sufficient numbers of students enroll in higher research degrees across all disciplines. ${ }^{15}$ A concern is that there may be insufficient academic workforce in the near future as retiring academics leave their posts. Compounding the concern for pharmacy practice academia in Australia is the recent expansion in number of pharmacy schools and of students enrolled in the professional degrees. Therefore, there is a need for research to be conducted within pharmacy schools aimed at understanding how to facilitate students' interest in pursuing a career in PPR.

It is to be expected that student experience during undergraduate curriculum would have a notable effect on final-year students' career expectations and goals. This expectation is supported by Wilson et al's study conducted in the United Kingdom, where final-year pharmacy students' perceptions of the main influence on their career choice were ranked in the following order: course content, hospital pharmacy visits and placements, and pharmacy practice lecturers. ${ }^{16}$ However, students enrolled in professional degree program at The University of Sydney reported that they had limited opportunities to actively participate in PPR during the curriculum or on placement. ${ }^{17}$ Within that degree, students can gain specific research training through the honors program (around $15 \%$ ), and approximately half of the students conduct projects related to pharmacy practice. However, pharmacy practice topics are delivered in depth during the third and fourth years where research-led teaching is intended to introduce students to the concepts around the design, conduct, and critical evaluation of PPR findings. Therefore, many students may be exposed to the concept of PPR through interactions with pharmacy practice academics, particularly toward the end of the degree. A major focus of this paper is, therefore, the social learning about PPR that occurs as a consequence of students' formal and informal contact with PPR educators and that runs in tandem with the delivery of curriculum.
Kritikos and colleagues explored students' perceptions of PPR in a 4-year undergraduate pharmacy degree in a research-intensive pharmacy school. ${ }^{17}$ Their research was designed to develop and validate the measurement of these perceptions at various stages of students' progression through the curriculum. While this research explored students' perceptions, it did not attempt to relate these perceptions to final-year students' career goals in PPR. This study builds on previous research to explore the relationship between; students' perceptions of the extent to which faculty members portray favorable attitudes towards PPR and their career goals centered on PPR. ${ }^{17}$

Bandura's social cognitive theory (SCT) was used as a framework for the present study because it recognizes that an individual's thoughts and behaviors have a social context. ${ }^{18}$ These thoughts and behaviors are impacted by a combination of observation and direct experience. Further, SCT has been used as a framework to develop an educational theory of how social learning influences graduate students' career intentions. ${ }^{19}$ The theory holds that goal systems play an important role in the self-regulation of behavior. ${ }^{20}$ In the context of career-related goals, making decisions to apply for or accept a particular position is the most specific goal. Other goal-setting activities occur earlier in the process and include holding aspirations, developing career plans, and formulating (and stating) intentions. Turning to the present study, if Australian final-year pharmacy students wished to pursue a career in PPR, the most logical and salient step for them would be to consider undertaking a higher degree in PPR, at some stage after graduation. It could be argued that students may consider a career in PPR without undertaking a higher degree. However, the authors believe that the most conceptually accessible step towards achieving this career goal would be to do a higher degree. Therefore, the aim of the research was to develop and test a model, based on SCT, of final-year students' intention to undertake a higher degree in PPR after graduation.

\section{METHODS}

In essence, SCT posits that whether a person is motivated to undertake a particular activity may be influenced by their expectations of their capacity to undertake the activity (self-efficacy) and their expectations about the outcome of participating in the activity (outcome expectancy). ${ }^{18}$ A diagram of the hypothesis generated from this model is provided in Figure 1. In the present case, self-efficacy may be described as students' perception of their ability to conduct PPR. To undertake PPR after graduation, consistent with SCT, students would benefit from self-confidence in their understanding of how to design, conduct, and evaluate the 


\section{American Journal of Pharmaceutical Education 2016; 80 (6) Article 95.}

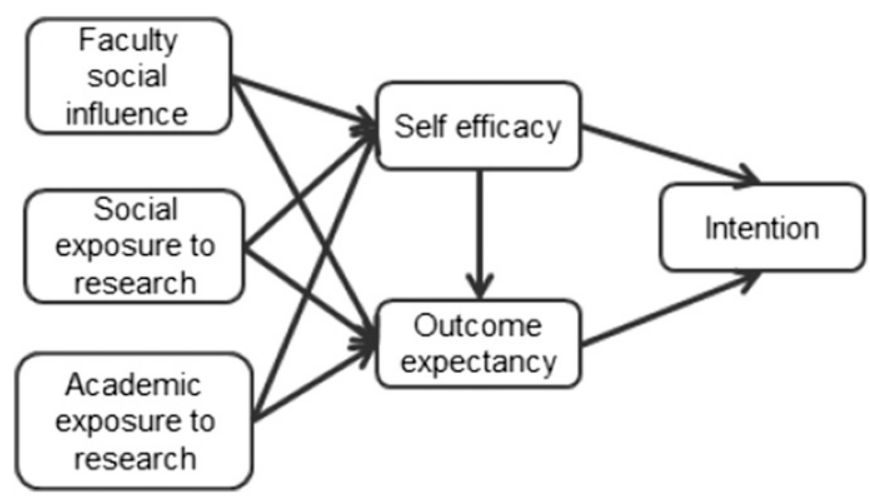

Figure 1. Conceptual Model of Final-year Students' Intention to Undertake a Higher Degree in Pharmacy Practice Research

findings of PPR in the context of clinical practice. It was hypothesized that having high self-efficacy would positively influence intention. In the theory, self-efficacy is thought to influence a person's intention to act both directly and indirectly by increasing outcome expectancy. ${ }^{20}$ In this context, outcome expectancy may be described as students' expectations of whether conducting PPR research after graduation would be enjoyable and beneficial for them and their career. We hypothesized that having high positive outcome expectancy would positively influence intention.

An essential element of SCT is the social influence that others have on our thoughts and feelings about our goal behavior, which occurs during our vicarious learning experiences. ${ }^{21}$ Social influence, which is an element of persuasion, occurs when individuals are led or mentored by persons whom they believe have the capability to perform the task of interest. Self-efficacy may be markedly influenced by the modeling behavior and verbal persuasion of such individuals. ${ }^{21}$ In the present context, "faculty social influence" is defined as students' perceptions of the extent to which their PPR teachers discuss and emphasize PPR in the undergraduate teaching environment. We hypothesized that high levels of faculty social influence would have a positive effect on self-efficacy and a direct or indirect effect on outcome expectancy.

Our vicarious learning experiences of research should be more salient and influential if we are actually exposed to the processes of conducting research. Assuming that learning experiences about research were positive, consistent with SCT, its effect would be to increase self-efficacy and outcome expectancy. Exposure to research could occur during the course of the bachelor of pharmacy (BPharm) degree program, and this was named "academic exposure to research." Exposure to research could also occur through experiences unrelated to formal education, such as contact with family and friends, which was named "social exposure to research."
This was a cross-sectional study using the analytical method of structural equation modeling (SEM), chosen because it allows researchers to test hypotheses between latent variables, or unobserved variables. Latent variables are typically psycho-social constructs and in the present study were self-efficacy, outcome expectancy, faculty social influence, and intention. While latent variables cannot be measured directly, they may be estimated by modeling relationships between observed variables and the latent variable. The advantage of SEM is that it enables researchers to test hypotheses while simultaneously providing evidence of the reliability of the relationship between the observed variables and the latent variables. ${ }^{22}$ The SEM techniques were performed and reported in accordance with Schreiber. ${ }^{23}$

Respondents were eligible for inclusion in this study if they were enrolled in the final year of the 4-year pharmacy undergraduate program at the University of Sydney in Australia. To provide sufficient sample size the survey was conducted in 2012 and repeated in 2013.

The questionnaire was adapted from Winans and Madhavan. ${ }^{24}$ It contained 25 psycho-social items, 16 providing demographic and educational background information, and five allowing for free-text responses (not reported in the present study). The demographic information collected in the questionnaires included age, gender, and whether the respondent was born in Australia. Other information relevant to educational background was probed using responses to yes/no questions such as whether the student had received a scholarship to study or had an educational loan to repay. The small numbers of students enrolled in the honors program were not identified to ensure anonymity among respondents.

Measuring whether students perceived academic and social exposure to research to be a positive experience would require generating new measurement scales, which was beyond the scope of the study. Exposure to research was conceptualized as either exposed or not. Academic exposure to research was measured by asking respondents a single question "Have you been exposed to or involved in any research during your education" with a yes/no response $(1=$ yes, $0=$ no). There were four items designed to determine the level to which a student had been exposed to (any) research through social contact with family or friends: "Are any immediate family members involved in research? Are any other family members involved in research? Are any of your friends involved in research? Do you have a mentor involved in research?" An index of social exposure to research was formed by summing the responses to the four yes/no questions $(1=$ yes, $0=$ no). Thus, the index score could theoretically range from zero to 4 . 


\section{American Journal of Pharmaceutical Education 2016; 80 (6) Article 95.}

For all the other items used in the SEM, respondents provided their level of agreement with statements on a 5-point Likert scale. Following the guidance of Rossiter, a single item was selected for the dependent variable because intention to undertake a higher degree in PPR (intention) is a relatively concrete attribute. ${ }^{25}$ Respondents were asked to provide their level of agreement to the statement "I am likely to pursue a pharmacy practice research degree (eg, $\mathrm{PhD} / \mathrm{MPhil}$ ) in the future." Faculty social influence, outcome expectancy, and self-efficacy were eliciting attributes, ${ }^{25}$ which required the use of multiple items to ensure the measures probe the set of beliefs that comprise the construct. Therefore, the remaining items were those used in Winans' and Madhavan's study. ${ }^{24}$ The psychometric properties of the measurement scales were subsequently explored in research conducted by Kritikos et al, among 853 University of Sydney students across the four years of the undergraduate program. ${ }^{17}$ Self-efficacy was measured with three items. In Kritikos et al's research, this construct was called "confidence to do PPR" and had acceptable reliability (Cronbach alpha=0.77). ${ }^{17}$ Outcome expectancy was measured with seven items. In Kritikos et al's research, three items were removed from this scale to reduce crossloadings, leaving just four items. In the present study, all seven items were included because the three deleted items explored students' perceptions regarding the benefit of doing PPR in relation to employment goals. Inclusion of these items was in keeping with the original meaning of outcome expectancy as defined by Bandura. Faculty social influence was measured with three items. In the research of Kritikos et al, this construct was called "faculty involvement of students in PPR" and had acceptable reliability (Cronbach alpha $=0.70)$.

All enrolled students were invited to complete the voluntary, anonymous survey during tutorial time in the final week of the last semester. Completion of the survey instrument implied informed consent. No incentives were offered to respondents. Approval for the project was given by the University of Sydney Human Ethics Committee.

For descriptive statistical analyses and exploratory factor analysis (EFA), SPPS 21.0.0.0 (SPSS Inc., Chicago, IL) was used. Confirmatory factor analysis (CFA) and structural equation modeling (SEM) were performed with AMOS 21.0.0 (SPSS Inc., Chicago, IL) using a maximum likelihood (ML) estimator. ${ }^{17}$ Structural equation modeling with ML estimation requires the presence of multivariate normality for dependent variables. Therefore, prior to performing the CFA, items intended to be used as dependent variables in the structural model were examined for evidence of skewness and kurtosis. Prior to using the multi-item measurement scales for CFA or
SEM, a maximum likelihood EFA with oblique rotation was performed on the data from the sample of 2012 in order to test whether the scales were unidimensional. Since there was only one indicator for the dependent variable, a latent variable was created in which the error term for the indicator was fixed at (1-reliability) $x$ observed variance, where the reliability was estimated to be 0.85 .

Convergent validity of the multi-item scales was assessed by inspection of the results from CFA. Standardized factor loadings should exceed 0.50 with significance to demonstrate high convergence on a common point. ${ }^{26}$ In addition, the average variance extracted should equal or exceed $50 \%{ }^{26}$ The composite reliability (CR) of these scales was computed using the formula suggested by Fornell and Larcker, ${ }^{27}$ where values equal to or greater than 0.7 indicate that the construct of the model is reliable. $^{26}$ Discriminant validity was assessed using the paired construct method of Anderson and Gerbing. ${ }^{22}$ The technique of factorial invariance was employed to search for consistency in factor structure for each of the two groups of students $(2012,2013) .{ }^{28}$ According to $\mathrm{Wu}$ et al, data from different groups may be considered essentially equivalent and therefore pooled when strict invariance is demonstrated. ${ }^{29}$ Using the method of Westlund, ${ }^{30}$ with four latent constructs and 14 indicators (including the dependent variable), a sample size of more than 313 was deemed necessary to detect a minimum effect size of 0.20 with a power of 0.8 and $p<0.05$. To estimate the significance of direct and indirect effects in the structural model, the Bootstrap method was employed. ${ }^{31}$

\section{RESULTS}

Questionnaires were received from 183 of the 253 students enrolled in 2012 and 203 of the 261 students enrolled in 2013, giving response rates of $72 \%$ and $78 \%$, respectively. Descriptive statistics of the educational and background demographics of the sample are provided in Table 1. Chi-square tests revealed no significant differences between groups $(p<0.05)$ for any variable with one exception: compared with students from 2012, those in 2013 were more likely to have had a mentor involved in research. Overall, $43 \%$ of students reported that they had been exposed to research during their education. The index of social exposure to research ranged from 0 to 4 and the median [IQR] was 1[1] indicating that students most commonly had a single relative or friend involved in research.

Means and standard deviations for the belief measures from each group are presented in Table 2. Independent sample $t$ tests revealed that the mean score for each belief measure was not significantly different between groups $(p<0.05)$. The following provides some descriptive 


\section{American Journal of Pharmaceutical Education 2016; 80 (6) Article 95.}

Table 1. Demographics and Educational Background of Respondents

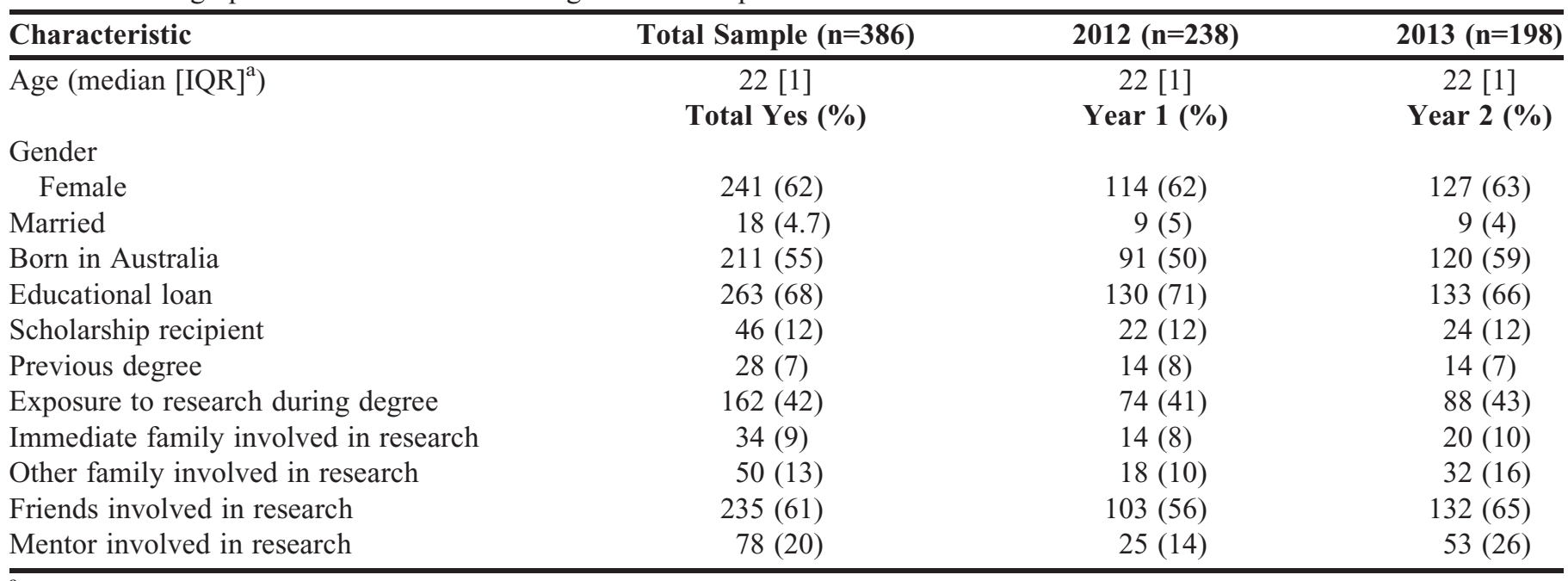

${ }^{\mathrm{a}} \mathrm{IQR}=$ interquartile range

statistics of the belief measures for the pooled data. For all outcome expectancy variables, the median score was either 2 or 3 and the mean (SD) scores ranged between $2.00(1.00)$ for OE2 (enjoy reading PPR literature) and 2.48 (1.00) for
OE6 (would enjoy working on a PPR project). This indicated that overall, respondents agreed to some extent that doing PPR would provide positive outcomes. For all selfefficacy variables, the median score was either 2 or 3 and

Table 2. Descriptive Statistics of Psycho-Social Variables ${ }^{\mathrm{a}}$

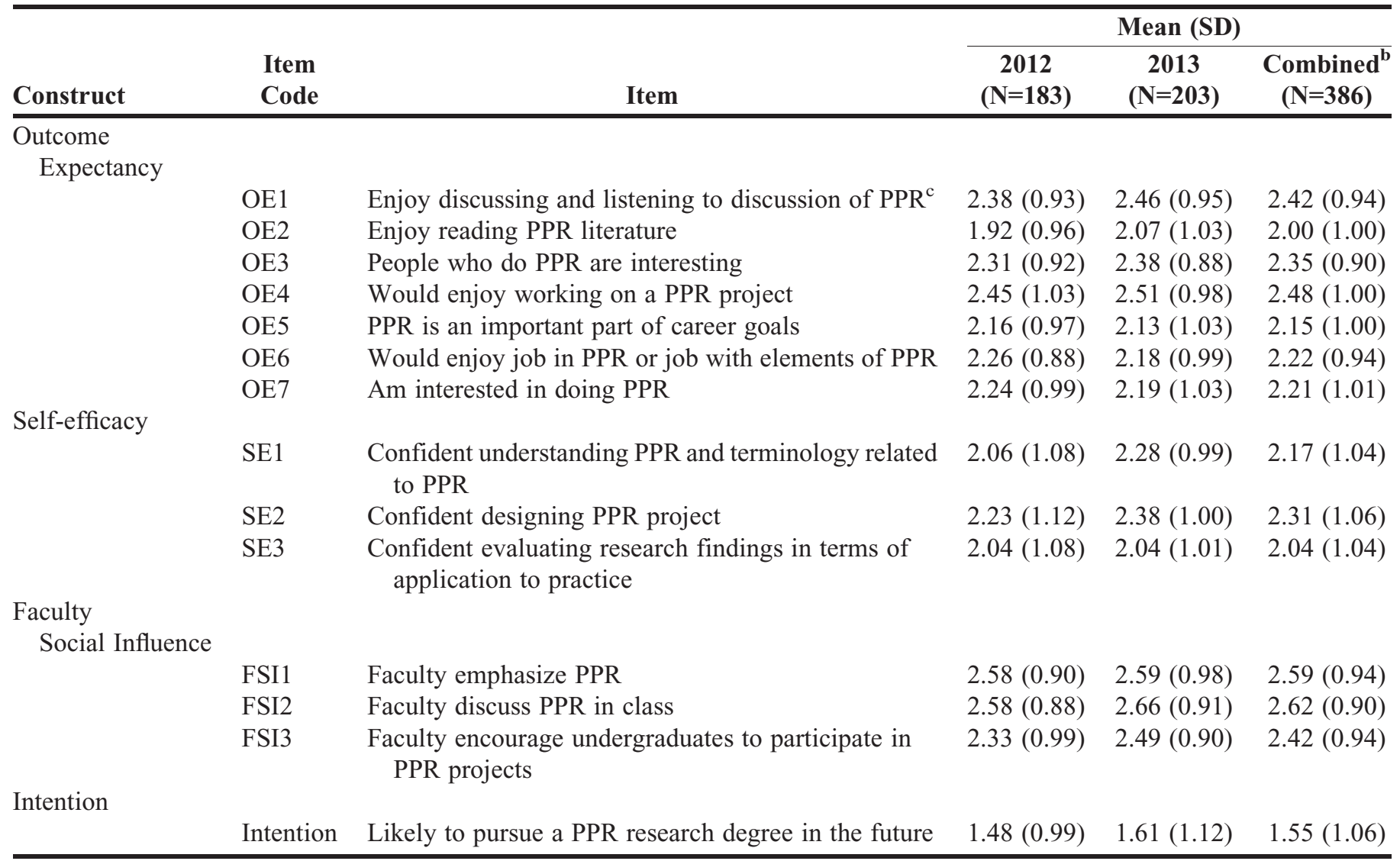

${ }^{a}$ Responses available were: strongly disagree $=0$, disagree $=1$, neither disagree nor agree $=2$, agree $=3$, strongly agree $=4$

${ }^{\mathrm{b}}$ Using independent samples $t$ tests, there were no significant differences between groups for any variable $(p<0.05)$

${ }^{\mathrm{c}} \mathrm{PPR}=$ pharmacy practice research 


\section{American Journal of Pharmaceutical Education 2016; 80 (6) Article 95.}

the mean (SD) scores ranged between 2.04 (1.04) for SE3 (confident evaluating research findings in terms of application to practice) and 2.31 (1.06) for SE2 (confident designing PPR project). This indicates that overall, respondents felt somewhat confident to do PPR. For all faculty social influence variables, the median score was 3 and the mean (SD) scores ranged between 2.42 (0.94) for FSI3 (faculty members encourage undergraduates to participate in PPR projects) and 2.62 (0.90) for FSI2 (faculty members discuss PPR in class). This indicates that overall, respondents provided a mild level of agreement that faculty members positively encouraged interest in PPR activities. For intention, the median score was 2 and the mean (SD) was 1.55 (1.06) indicating that overall, respondents provided a mildly negative to neutral indication that they were likely to pursue a PPR degree. Inspection of dependent variables in the SEM revealed that skewness and kurtosis statistics were less than or equal to an absolute value of 1 . There were no missing data. Examination of the correlation matrix revealed that no relationships were above 0.70 , so multicollinearity was not considered problematic. The results of the EFA revealed that, as expected, there were three factors with Eigenvalues above 1 , which explained $57 \%$ of the variation. All 13 items loaded onto their respective factors with loadings ranging from 0.60 to 0.91 , with no cross-loadings above 0.3 . This indicates that each of the scales were unidimensional and potentially suitable for SEM.

Inspection of the CFA results showed that the variances of the indicator variables loading onto each latent construct were significant. All of the factor loadings were greater than or equal to 0.5 . The parameter estimates and the goodness of fit indices indicated that overall, the measurement model was a reasonable but not a good fit for the data [Chi-square $=291, \mathrm{df}=92, p<0.001$, chi-square/ $\mathrm{df}=3.16, \mathrm{CFI}=0.94, \mathrm{TLI}=0.92, \mathrm{RMSEA}=0.075(90 \%$ confidence interval $=0.065,0.085)]$. Inspection of the modification indices revealed significant correlations between the error terms for OE5 (setting career goals including PPR) and OE6 (enjoy working in PPR). These items were the only items that explored students' expectations in relationship to employment, and so it is reasonable to assume that another unmeasured variable related to expectations about employment in general could cause these items to correlate. A new model was run allowing the error terms between OE5 and OE6 to correlate. While fit statistics were improved [chi-square $=269, \mathrm{df}=691$, $p<0.001$, chi-square $/ \mathrm{df}=2.96, \mathrm{CFI}=0.95, \mathrm{TLI}=0.93$, RMSEA $=0.073 \quad(90 \%$ confidence interval $=0.062$, $0.081)$, the model failed to achieve the targets set. Inspection of the modification indices revealed significant correlations between the error terms for OE1 (Enjoy discussing about and listening to discussion of PPR) and OE2 (reading about PPR). These items explored outcomes related to communicating about PPR and so it is reasonable to assume that another unmeasured variable related to communication tasks could cause these items to correlate. A new model was run that also allowed the error terms between OE1 and OE2 to correlate. The results indicated that this final model was a good fit for the data [chisquare $=239, \mathrm{df}=90, \quad p<0.001, \quad$ chi-square $/ \mathrm{df}=2.66$, $\mathrm{CFI}=0.96, \mathrm{TLI}=0.94, \mathrm{RMSEA}=0.066(90 \%$ confidence interval $=0.056,0.076)]$.

Convergent validity of the multi-item constructs was established as average variances extracted were greater than $50 \%$ and composite reliability were greater than 0.70 . Standardized and unstandardized factor loadings, construct validities, and average variances extracted are presented in Table 3. Discriminant validity was demonstrated: when

Table 3. Confirmatory Factor Analysis, Pooled Data $(\mathrm{N}=386)^{\mathrm{a}}$

\begin{tabular}{lccccc}
\hline Item & $\begin{array}{c}\text { Standardized } \\
\text { Regression Weights }\end{array}$ & $\begin{array}{c}\text { Unstandardized } \\
\text { Regression Weights (URW) }\end{array}$ & $\begin{array}{c}\text { Standard Error } \\
\text { of URW }\end{array}$ & $\begin{array}{c}\text { Construct } \\
\text { Reliability }\end{array}$ & $\begin{array}{c}\text { Average Variance } \\
\text { Extracted }\end{array}$ \\
\hline OE1 & 0.70 & 1.00 & & 0.88 & $55.7 \%$ \\
OE2 & 0.68 & 0.97 & 0.068 & & \\
OE3 & 0.68 & 0.91 & 0.075 & & \\
OE4 & 0.82 & 1.18 & 0.082 & & \\
OE5 & 0.67 & 0.99 & 0.083 & & \\
OE6 & 0.70 & 1.07 & 0.085 & & \\
OE7 & 0.81 & 1.21 & 0.085 & & $5.9 \%$ \\
SE1 & 0.77 & 1.00 & 0.073 & & \\
SE2 & 0.81 & 1.11 & 0.067 & & \\
SE3 & 0.84 & 1.04 & & & \\
FSI1 & 0.74 & 1.00 & 0.092 & & \\
FSI2 & 0.84 & 1.07 & 0.079 & & \\
FSI3 & 0.65 & 0.87 & &
\end{tabular}

${ }^{\mathrm{a}} \mathrm{OE}=$ outcome expectancy; $\mathrm{SE}=$ self-efficacy; FSI=faculty social influence 


\section{American Journal of Pharmaceutical Education 2016; 80 (6) Article 95.}

the covariance between each pair of constructs was fixed to 1 , there was a significant $(p<0.05)$ increase in chi-square. Results of the test for factorial invariance revealed that strict invariance was demonstrated as the RMSEA $=0.05$ and the $\Delta \mathrm{CFA}=0.007$.

The parameter estimates and the goodness of fit indices indicated that overall, the SEM was a reasonable fit for the data. Apart from the significant chi-square $=246.5$, $\mathrm{df}=93, p<0.001$, model fit indices were good for the measurement model [chi-square $/ \mathrm{df}=2.65, \mathrm{CFI}=0.94$, $\mathrm{TLI}=0.93, \mathrm{RMSEA}=0.065(90 \%$ confidence interval $=$ $0.056,0.075)]$. The model predicted $55 \%$ of the variation in intention. Figure 2 provides the results of hypothesis testing. Outcome expectancy had a strongly positive effect on intention $(\beta=0.72, p=0.004)$. Self-efficacy had no significant effect on intention but had a moderate indirect effect on intention $(\beta=0.39, p=0.004)$ through a strong effect on outcome expectancy $(\beta=0.54, p=0.004)$.

Faculty social influence had a moderate effect on selfefficacy $(\beta=0.29, p=0.004)$, no significant direct effect on outcome expectancy, and an overall small but significant indirect effect on intention $(\beta=0.15, p=0.006)$. The index estimating social exposure to research (SER) had no significant effect on any variable in the model. Inspection of the modification indices revealed that no direct path between FSI and intention or between SER and intention would improve model fit. Academic exposure to research had a weak and marginally significant negative effect $(\beta=$ $0.12, p=0.04)$ on outcome expectancy but no significant indirect effect on intention.

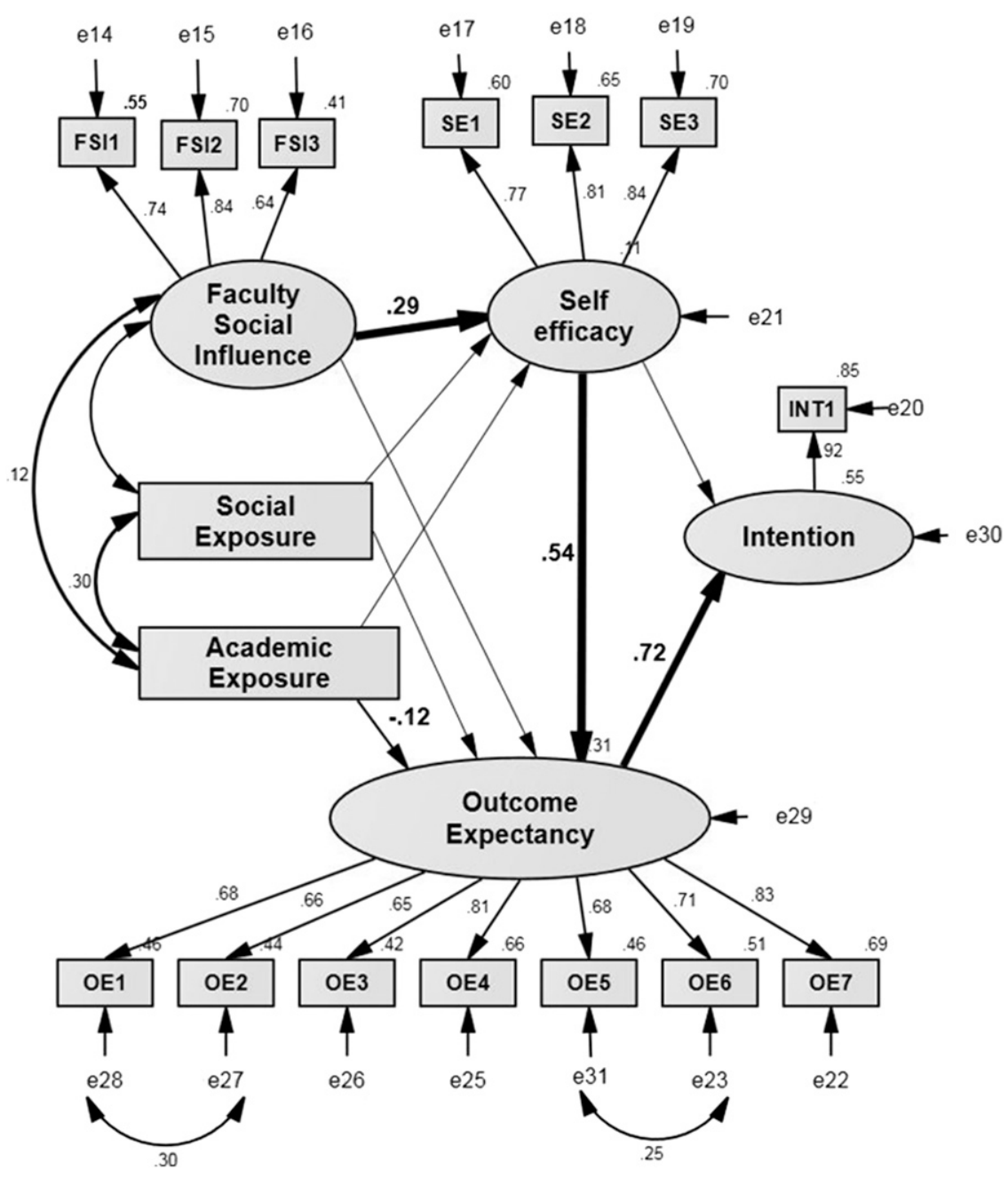

Figure 2. Structural Equation Model of Intention to Undertake a Higher Degree in Pharmacy Practice Research. Lines with numbers indicate significant paths with beta weights $(\mathrm{p}<0.05)$. Lines without numbers indicate nonsignificant paths. The numbers outside the boxes indicate the squared multiple correlations. Chi-square $/ \mathrm{df}=2.78, \mathrm{CFI}=0.94, \mathrm{TLI}=0.93, \mathrm{RMSEA}=0.068(90 \%$ confidence interval $=0.058,0.079)$. Predicated $11 \%, 31 \%$, and $55 \%$ of the variation in self-efficacy, outcome expectancy, and intention, respectively. Item labels: FSI = faculty social influence; SE = self-efficacy; OE $=$ outcome expectancy; INT=intention; $\mathrm{e}=$ error term. 


\section{American Journal of Pharmaceutical Education 2016; 80 (6) Article 95.}

\section{DISCUSSION}

This study demonstrated that overall, students indicated low intention to undertake a higher degree in PPR (intention). Using structural equation modeling to test a model grounded in social cognitive theory, this study explained a high degree of the variation in students' stated intention. Students' expectations about the personal benefits of doing PPR (outcome expectancy) and their confidence in their abilities to undertake the tasks involved in PPR (self-efficacy), were instrumental in influencing intention. Importantly, faculty members had a key role in moulding students' intention through social influence. Students' perceptions that faculty members discussed and emphasized PPR in their teaching and encouraged students to participate in PPR (faculty social influence) increased students' self-efficacy. However, students' self-reported exposure to PPR during their candidature had no direct or indirect effect on intention. Exposure to the research process through contact with family or friends also had negligible effect on intention.

This study notes a low overall level of intention of final-year pharmacy students to undertake a higher degree in PPR, despite the fact that these students were enrolled at a research-intensive university with a strong history of research-led teaching. In some ways, this may not be surprising. In Australia, following graduation a majority of students undertake a 1-year internship to become a registered health provider. The intern year consists of working under supervision with a registered pharmacist while completing an approved intern training program such as a graduate certificate and/or diploma of pharmacy. It is likely that, near the completion of their undergraduate degree, students' most salient career expectations focus on the supervised practice component of the intern year, either within hospital or community pharmacy. ${ }^{32}$ Recent Australian research suggests that pharmacy students' expectations of the graduate year tend to focus on the formation of a strong professional identity. ${ }^{33}$ Regardless of the overall level in stated intention, there was a degree of variation and clearly some students were more interested in pursuing a higher degree in PPR than others.

The most proximal variable to influence students' intention was their beliefs that participating in PPR projects in the workplace would be enjoyable and that PPR is an important part of their career goals (outcome expectancy). Students tended to rate these beliefs neutrally to mildly positive. Previous cross-sectional research investigating perceptions of students towards PPR at different stages of the pharmacy program showed that students tended to consider PPR more enjoyable later into the degree. ${ }^{17}$ As students develop their knowledge and skills in pharmacy practice, they may view PPR as more relevant. In terms of encouraging students to pursue career goals related to PPR, educational strategies should focus on improving their perceptions of PPR as a career choice and making PPR more pertinent to practice and therefore more salient. Ideally, this should occur throughout the undergraduate program and particularly towards the final stages of the curriculum.

While students' confidence to conduct PPR (selfefficacy) influenced intention, it did so indirectly by increasing outcome expectancy, which in turn increased intention. That is, while self-efficacy was important, there was no direct effect on intention. The reason for this is, to some extent, consistent with SCT. In terms of the development of career goals, Lent et al explained that when the target behavior relates to an aspirational goal, rather than to an urgent choice, outcome expectancy is more likely to be directly relevant. ${ }^{19}$ In the present case, since students' prospects of doing PPR seemed a little remote while they focused on the graduate year, their self-confidence to conduct PPR was less directly important to their career goals in PPR than thinking about the benefits of doing so in the future. Nevertheless, and consistent with the application of SCT to career goal development, self-efficacy was important because it improved outcome expectancy. Regardless of the route of influence, having the self-confidence to do PPR is important in determining whether students find engaging in PPR enjoyable, develop an interest in PPR, and create intention to include this in their career path. Social cognitive theory predicts that self-efficacy also has a role in turning stated intentions into actual career choice. Students tended to rate their self-confidence as neutral to mildly positive; thus, there is scope to increase students' self-confidence to do PPR.

One of the most important findings of this study was that by using SEM, students' perceptions of whether faculty members discussed, emphasized, and encouraged students to participate in PPR (faculty social influence) indirectly increased students' intention. This indirect effect occurred initially by increasing students' self-efficacy, which increased their outcome expectancy, which in turn increased intention. The relationship between faculty social influence and self-efficacy was predicted by the model grounded in SCT because of the strong effect social influence can have on a person's self-confidence to select and develop career goals. The SEM demonstrated there was no direct effect of faculty social influence on outcome expectancy. This can be interpreted to indicate that faculty members can influence students' perception of the benefits of a career in PPR, but only if students develop some confidence in conducting PPR. Once again, this highlights the central role of self-efficacy in career 


\section{American Journal of Pharmaceutical Education 2016; 80 (6) Article 95.}

goal-setting, as predicted by Bandura. That simply discussing and emphasizing PPR does not ensure that faculty members can influence students' orientation toward a career in PPR unless confidence is developed, highlights the need for faculty members to focus on improving students' technical competence in research while communicating enthusiastically with students about their own research. Ideally, students should be exposed to the types of successes that may be achieved through sustained effort and to which academics aspire, such as ground-breaking publications, awards, grants, and career paths. They should hear the ways with which methodological problems in PPR are overcome. They should feel motivated to generate the research questions facing the next generation of consumers and their relationships with medications and start thinking about ways with which the research questions could be addressed.

So, while it is appropriate and mandated for students to learn research skills, whether or not the educational setting of university moulds students' career goals towards PPR appears to depend on the extent to which faculty members contextualize PPR and motivate students to participate in it. For faculty members teaching in pharmacy degree programs, this is an important finding because, contrary to the findings of Winan et al, ${ }^{24}$ simply being exposed to research during coursework or being exposed socially through mentors, family, and/or friends had little effect on any variables in the SEM. To some extent, this finding is also in contrast to Kiersma et al's qualitative research supporting the notion of providing students with research mentors during undergraduate or PharmD degrees. ${ }^{34}$ In that study, the presence of a research mentor appeared to improve students' perceptions of research and their confidence to do research. ${ }^{34}$ In the present study, only $20 \%$ of students reported that they had mentors involved in research. Thus it appears that there is plenty of scope to improve the rate of mentoring within the BPharm program at this university. Pharmacy students value having access to research mentors. ${ }^{34}$ Strategies that help students develop an interest in research include being able to choose the mentor and for the mentor to be available. ${ }^{34}$ Students' perception of the availability of mentors could be supported with regular, structured discussions regarding PPR. ${ }^{34}$ Only $42 \%$ of students reported being exposed to research during the degree, despite the fact that the curriculum was designed to be research-oriented. Perhaps research exposure for these students needs to be made more explicit within the curriculum. By the end of the fourth year at the university, students are expected to have critically evaluated and used the research evidence-base to complete learning tasks centered on a range of pharmacy practice issues on which faculty members conduct research. These issues can include pharmacotherapeutics, patient education, consumer decision-making, communication processes, and self-management strategies within complex interpersonal situations. Opportunity exists for faculty members to highlight their own and their peers' research in discussions around these and many other PPR topics.

This research shows that few students have mentors involved in PPR. A minority report having been exposed to PPR and overall, few students are formulating career goals centered on PPR. Simply providing students with exposure to PPR during the BPharm degree is unlikely to influence them to include PPR in their career goals. What is likely to increase students' career orientation towards PPR is having greater access to faculty members who engage with them in topics around PPR. Academics need to encourage and mentor students in research if more pharmacists are to engage in research in the future.

The strengths of the study include the high response rate, the absence of missing data, and excellent convergent and discriminant validity of the measurement scales. The sample was representative based on current national student population data reflecting the increasing number of females entering the profession. ${ }^{14}$

The present study had a cross-sectional design, and this may be considered a limitation. While SEM is useful to test hypotheses among latent variables, in a cross-sectional design such as this, causality must be implied. Further, the direction of influence between self-efficacy and outcome expectancy requires some consideration. In the context of career goals, Bandura asserts that self-efficacy influences outcome expectancy. ${ }^{18}$ This view is shared by Lent et al. ${ }^{19}$ However, Maddux and Rogers' protection motivation theory (PMT) contends that the direction of influence between self-efficacy and outcome expectancy is reversed. ${ }^{35}$ They argue that people's expectations about the outcomes of participating in a task shape their expectations of whether they have the capability to complete the task. This theory is more typically conceptualized around goals which are motivated by fear appeals, such as quitting smoking because of the risk of lung disease and exercising to reduce the risk of cardiovascular disease. ${ }^{36}$ There remains an element of uncertainty in the true direction of the causal relationship between these constructs and the manner in which the controversy could be resolved. ${ }^{37}$ In a cross-sectional study such as this, it is not possible to determine the direction of influence. Given that Bandura and Lent and colleagues used SCT to conceptualize and conduct research in career goals, the present study hypothesized that self-efficacy influences outcome expectancy. Future research could be conducted to capture longitudinal data from students during and after graduation to confirm these findings. 


\section{American Journal of Pharmaceutical Education 2016; 80 (6) Article 95.}

A limitation of the methodology relates to the inclusion of a single question to probe students' career goals in PPR, namely intention. The disadvantage of using a singleitem indicator is that it is not possible to use CFA to test for convergent validity. Furthermore, it is acknowledged that intention does not equal behavior. Future longitudinal research could build on our conceptual framework to explore the link between student perceptions and career pathways.

The generalizability of the findings from this study may be limited because the results are based on self-reports and ratings by participants from a single Australian 4-year undergraduate pharmacy program. Future research is currently underway in samples of students from other Australian pharmacy degree programs.

Students' exposure to PPR was self-reported, so the results should be interpreted with this in mind. Further, the dichotomous variables probing academic and social exposure to research limit the interpretation of results. For example, whether the experience of research during the degree program was positive or negative could depend on the outcomes of doing the research. Factors such as the success of the project they were involved in and the grades that were achieved could influence whether students felt confident about doing PPR and whether a career in PPR was perceived to be a positive thing. Obtaining data from students about their grades achieved in research activities was outside the scope of the project. Future studies could address this issue by matching student performance with survey data and by developing and validating measurement scales for students' perceptions of PPR experience, rather than simply exposure to research.

The results of the CFA suggest that model fit was improved by allowing two pairs of items within the outcome expectancy scale to have correlated error terms. While the manuscript provided justification for allowing these correlations, the necessity to do so suggests some redundancy in the items affected. Future research should consider removing either OE1 or OE2 and either OE5 or OE6 to create in a more parsimonious scale without substantively influencing the meaning of outcome expectancy.

\section{CONCLUSION}

This study showed that pharmacy practice educators have a key role in influencing pharmacy students' orientation towards undertaking PPR as a career. Through social influence, pharmacy practice educators can increase students' self-confidence to undertake PPR and indirectly increase their perceptions of including PPR in their career goals. Simply providing students with exposure to PPR appears to have little influence on their perceptions of PPR as a career or their intention to undertake a higher degree in PPR after graduation. To increase pharmacy students' orientation towards PPR as a career path, pharmacy practice educators need to contextualize their research and where possible provide links between research and practice. Mentoring programs in PPR are recommended.

\section{ACKNOWLEDGMENTS}

The authors wish to thank the undergraduate pharmacy students who participated in this study. There are no conflicts of interest in authorship of this article. This research received no specific grant from any funding agency in the public, commercial, or not-for-profit sectors.

\section{REFERENCES}

1. Hepler CD, Strand LM. Opportunities and responsibilities in pharmaceutical care. Am J Hosp Pharm. 1990;47(3):533-543.

2. Federation International Pharmaceutical. FIP statement of policy on good pharmacy education practice. The Haage, The Netherlands 2000 .

3. Brazeau GA, Meyer SM, Belsey M, et al. Preparing pharmacy graduates for traditional and emerging career opportunities. Am J Pharm Educ. 2009;73(8):Article 157.

4. Australian Pharmacy Council Ltd. Accreditation standards for pharmacy programs in Australia and New Zealand. https://www. pharmacycouncil.org.au/education-providers/degree-programs/ accredited-degree-programs/ Accessed August 9, 2016.

5. Accreditation Council for Pharmacy Education. Accreditation standards and guidelines for the professional program in pharmacy leading to the doctor of pharmacy degree. 2006. https://www.acpe-accredit. org/pdf/ACPE_Revised_PharmD_Standards_Adopted_Jan152006.pdf Accessed April 24, 2015.

6. General Pharmaceutical Council. Future pharmacists. Standards for the initial education and training of pharmacists. 2011. http:// www.pharmacyregulation.org/sites/default/files/Standards $\% 20$ for $\%$ 20the $\% 20$ initial\%20education $\% 20$ and $\% 20$ training $\% 20$ of $\%$

20pharmacists.pdf. Accessed April 24, 2015.

7. The Canadian Council for Accreditation of Pharmacy Programs. Standards for the first professional degrees in pharmacy programs.

2013. http://ccapp-accredit.ca/wp-content/uploads/2016/01/

CCAPP_accred_standards_degree_2014.pdf Accessed August 92016. 8. Lee MW, Clay PG, Kennedy WK, et al. The essential research curriculum for doctor of pharmacy degree programs.

Pharmacotherapy. 2010;30(9):966.

9. Fuji KT, Galt KA. Research skills training for the doctor of pharmacy in U.S. schools of pharmacy: a descriptive study. Int $J$ Pharm Pract. 2009;17(2):115-121.

10. Bahnassi A. The breadth and depth of formal research skills training within pharmacy program curricula in selected Arabic-speaking countries. Curr Pharm Teach Learn. 2015;7(3):417-423. 11. Bond C. The need for pharmacy practice research. Int J Pharm Pract. 2006;14(1):1-2.

12. Advanced Pharmacy Practice Framework Steering Committee. An advanced pharmacy practice framework for Australia. Canberra, Australia, 2012. www.advancedpharmacypractice.com.au. Accessed August 92016.

13. Advanced Pharmacy Practice Framework Steering Committee. Evaluation and credentialling of advanced practice pharmacists. Canberra, Australia, 2014. http://auspharmacist.net.au/documents/ apicon.pdf. Accessed August 92016 


\section{American Journal of Pharmaceutical Education 2016; 80 (6) Article 95.}

14. Health Workforce Australia. Australia's Health Workforce Series - Pharmacists in Focus. 2014. http://iaha.com.au/wp-content/ uploads/2014/03/HWA_Australia-Health-Workforce-

Series_Pharmacists-in-focus_vF_LR.pdf. Accessed August 92016. 15. Edwards D, Bexley E, Richardson S. Regenerating the academic workforce: the careers, intentions and motivations of higher degree research students in Australia: findings of the National Research Student Survey (NRSS). 2011. http:// research.acer.edu.au/higher_education/23. Accessed January $6,2014$.

16. Wilson K, Jesson J, Langley C, Hatfield K, Clarke L. Pharmacy undergraduate students: career choices and expectations across a four-year degree programme. Royal Pharmaceutical Society of Great Britain 2006.

17. Kritikos VS, Carter S, Moles RJ, Krass I. Undergraduate pharmacy students' perceptions of research in general and attitudes towards pharmacy practice research. Int J Pharm Pract. 2013;21

(3):192-201.

18. Bandura A. Social Foundations of Thought and Action: A Social Cognitive Theory. Englewood Cliffs, NJ: Prentice Hall; 1986. 19. Lent RW, Brown SD, Hackett G. Toward a unifying social cognitive theory of career and academic interest, choice, and performance. J Vocat Behav. 1994;45(1):79-122.

20. Bandura A. Self-efficacy: The Exercise of Control. New York, NY: W.H.Freeman; 1997.

21. Bandura A. Self-efficacy: toward a unifying theory of behavioral change. Psychol Rev. 1977;84(2):191-215.

22. Anderson JC, Gerbing DW. Structural equation modeling in practice: a review and recommended two-step approach. Psychol Bull. 1988;103(3):411-423.

23. Schreiber JB. Core reporting practices in structural equation modeling. Res Social Adm Pharm. 2008;4(2):83-97.

24. Winans KS, Madhavan S. Some factors influencing undergraduate pharmacy students' perceptions of and attitudes toward research related activities. Am J Pharm Educ. 1992;56 (1):29-35.

25. Rossiter JR. The C-OAR-SE procedure for scale development in marketing. Int J Res Market. 2002;19(4):305-335.
26. Hair Jr. JF, Black WC, Babin BJ, Anderson RE, Tatham RL. Multivariate Data Analysis. $6^{\text {th }}$ ed. Upper Saddle River, NJ: John Wiley and Sons; 2006.

27. Fornell C, Larcker DF. Evaluating structural equation models with unobservable variables and measurement error. J Market Res. 1981;18(1):39-50.

28. Cheung GW, Rensvold RB. Evaluating goodness-of-fit indexes for testing measurement invariance. Structural Equation Modeling: A Multidisciplinary Journal. 2002;9(2):233-255.

29. $\mathrm{Wu} \mathrm{AD,} \mathrm{Li} \mathrm{Z,} \mathrm{Zumbo} \mathrm{BD.} \mathrm{Decoding} \mathrm{the} \mathrm{meaning} \mathrm{of} \mathrm{factorial}$ invariance and updating the practice of multi-group confirmatory factor analysis: a demonstration with TIMSS data. Pract Assess Res Eval. 2007;12(3). http://pareonline.net/getvn.asp?v=12\&n=13. Accessed January 20, 2015.

30. Westland CJ. Lower bounds on sample size in structural equation modeling. Elec Comm Res App. 2010;9(6):476-487.

31. Cheung GW, Lau RS. Testing mediation and suppression effects of latent variables: Bootstrapping with structural equation models. Org Res Meth. 2008;11(2):296-325.

32. Shen G, Fois R, Nissen L, Saini B. Course experiences, satisfaction and career intent of final year pre-registration Australian pharmacy students. Pharm Pract. 2014;12(2):392.

33. Noble C, Coombes I, Nissen L, Shaw PN, Clavarino A. Making the transition from pharmacy student to pharmacist: Australian interns' perceptions of professional identity formation. Int J Pharm Pract. 2014 doi: 10.1111/ijpp.12155.

34. Kiersma ME, Hagemeier N, Chen AMH, Melton B, Noureldin M, Plake KS. A graduate student mentoring program to develop interest in research. Am J Pharm Educ. 2012;76(6):Article 104. 35. Maddux JE, Rogers RW. Protection motivation and self-efficacy: a revised theory of fear appeals and attitude change. J Exp Soc Psychol. 1983;19(5):469-479.

36. Floyd DL, Prentice-Dunn S, Rogers RW. A meta-analysis of research on protection motivation theory. J Appl Soc Psychol. 2000;30(2):407-429.

37. Williams DM. Outcome expectancy and self-efficacy: theoretical implications of an unresolved contradiction. Pers Soc Psychol Rev. 2010;14(4):417-425. 